\section{Leukotrienantagonist bei Aspirin-Asthma?}

Acetylsalicylsäure-sensitives Asthma, so eine Hypothese, könnte auf einer Überexpression des Enzyms LTC4-Synthase und einer dadurch gesteigerten Leukotriensynthese beruhen. Dann sollte die Gabe eines Cysteinyl-Leukotrienrezeptor-Antagonisten eine sinnvolle Therapieoption sein.

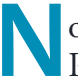
orwegische Studienärzte gaben 36 Patienten mit Aspirin-sensitivem Asthma über 4 Wochen randomisiert und doppelblind entweder $10 \mathrm{mg} / \mathrm{d}$ des Leukotrienantagonisten Montelukast oder Plazebo. Vor und nach der Therapie wurden ein nasaler Provokationstest mit Lysin-Acetylsalicylsäure (LASS) durchgeführt und die nasale Reaktion per akustischer Rhinomanometrie ermittelt.

$\mathrm{Zu}$ Studienbeginn reagierten alle Patienten nach LASS-Provokation mit erhöhtem nasalen Widerstand sowie ei- nem signifikanten Abfall des totalen nasalen Volumens. Bei Studienende blieb diese Reaktion bei den mit Montelukast behandelten Patienten fast vollständig aus, während die Patienten der Plazebogruppe wieder die bekannten nasalen Symptome zeigten.

Während der 4-wöchigen Therapiephase verbesserten sich bei den Patienten unter Verum auch nasale Funktionen und Symptomscore. Dieser Befund ist bemerkenswert, da die Patienten vor Beginn der Studie über mehrere Wochen

mit Glukokortikoiden behandelt worden waren. Trotzdem hatten sie offenbar immer noch eine leicht eingeschränkte $\mathrm{Na}$ senatmung, die sich erst durch den Leukotrienantagonisten besserte. Dadurch wird die Hypothese gestützt, dass Aspirin-sensitive Patienten erhöhte nasale Leukotrienwerte aufweisen. Eosinophilenzahl und ECP (eosinophil cationic protein) im Serum fielen durch die Verumbehandlung ebenfalls signifikant $a b$.

Fazit: Patienten mit Aspirin-sensitivem Asthma sind durch die Gabe des Leukotrienrezeptor-Antagonisten Montelukast vor nasalen Akutsymptomen bei LASS-Kontakt weitgehend geschützt. $b k$

Micheletto $C$ et al. Montelukast $10 \mathrm{mg}$ improves nasal function and nasal response to aspirin in ASA-sensitive asthmatics: a controlled study vs placebo. Allergy 2004; 59: 289-94

dagegen nicht (OR 0,95). Auch war die Lungenfunktion der Rauchersöhne schlechter als die der Rauchertöchter. Frauen zeigten dagegen vermehrt Wheezing-Episoden (OR 1,39) und auch Asthma im Erwachsenenalter (OR 1,28), wenn ihre Mütter während der Schwangerschaft geraucht hatten. Bei den Söhnen war dieser Zusammenhang nicht zu erkennen (OR 1,11 bzw. 0,98).

Der insgesamt schädlichere Einfluss

Respiratory Health Survey (ECRHS) wurden von 18.922 Personen aus 17 europäischen Ländern Daten zur Lungenfunktion gesammelt. Das elterliche Rauchverhalten der Teilnehmer wurde mit Hilfe eines Fragebogens ermittelt.

Bei $67 \%$ der Befragten hatte der Vater während ihrer Kindheit geraucht. Der Anteil der rauchenden Mütter variierte länderspezifisch stark: In Spanien hatten 3\% der Mütter, in Dänemark und den englischsprachigen Ländern bis zu $40 \%$ geraucht.

Wurden die Daten von Männern und Frauen gemeinsam ausgewertet, so ging primär der mütterliche Nikotinkonsum mit einem erhöhten Risiko für pfeifende Atemgeräusche (Odds Ratio [OR] 1,12) und verminderter Lungenkapazität einher. Das Risiko stieg signifikant, sofern beide Elternteile geraucht hatten. Es gab jedoch keine positive Korrelation zu chronischem Asthma im Erwachsenenalter.

Wurden die Daten geschlechtsspezifisch untersucht, so änderte sich das Bild nochmals: Männer hatten häufiger Wheezing-Anfälle erlebt, wenn ihre Väter geraucht hatten $(\mathrm{OR} 1,13)$, Frauen

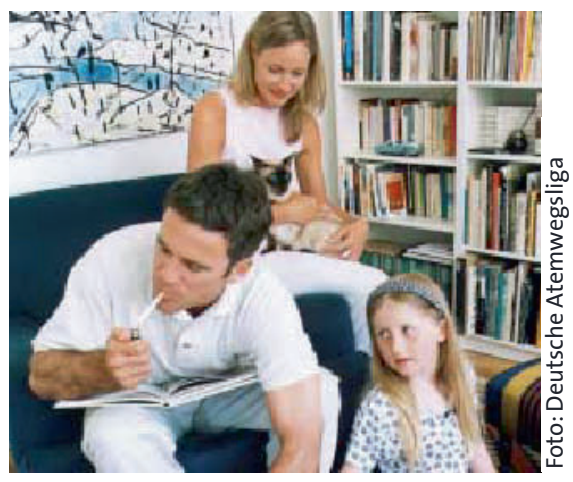

Ob er so seiner Tochter einen Gefallen tut? des mütterlichen Rauchens ist vermutlich einfach in dem intensiveren Kontakt zu den Kindern begründet. Eine mögliche Erklärung, warum das Rauchen während der Schwangerschaft vor allem die Mädchen trifft, ist eine frühere intrauterine Reifung der weiblichen Lungen.

Fazit: Passivrauchen schädigt sowohl während der Schwangerschaft als auch in den ersten Lebensjahren das kindliche Lungengewebe. Töchter leiden dabei offenbar mehr durch intrauterine, Söhne mehr durch postnatale Exposition.

Svanes $\mathrm{C}$ et al. Parental smoking in childhood and adult obstructive lung disease: results from the European Community Respiratory Health Survey. Thorax 2004; 59: 295-302 